\title{
FORMAÇÃO CONTINUADA EM UMA ESCOLA DE TEMPO INTEGRAL: NOTAS SOBRE UM ESTUDO DE CASO ${ }^{1}$
}

\author{
CONTINUING EDUCATION IN A FULL-TIME SCHOOL: NOTES ON A CASE STUDY \\ EDUCACIÓN CONTINUA EN UNA ESCUELA A TIEMPO COMPLETO: NOTAS SOBRE UN \\ ESTUDIO DE CASO
}

Elisangela da Silva Bernado ${ }^{1}$ Katia Regina Teixeira Vasconcellos ${ }^{2}$

\begin{abstract}
${ }^{1}$ Doutora em Educação pela PUC/RJ. Docente do Programas de Pós-Graduação em Educação da Universidade Federal do Rio de Janeiro (UNIRIO) - Rio de Janeiro - RJ - Brasil. ${ }^{2}$ Mestre em Educação pela Universidade Federal do Rio de Janeiro (UNIRIO) - Rio de Janeiro - RJ - Brasil.
\end{abstract}

Resumo: O artigo oportuniza refletir sobre a formação dos professores que atuam em uma escola, que atende aos cinco primeiros anos do ensino fundamental em tempo integral, e se essa formação é suficiente para proporcionar aos docentes uma formação mais completa com a participação desses profissionais em cursos, palestras e encontros formativos e formações continuadas em serviço, assim, traremos alguns apontamentos de como esses profissionais percebem mudanças em sua prática pedagógica. Como questão problema, destacamos: como a formação continuada oferecida pela rede municipal de educação altera (ou não) a prática do professor? Participaram do estudo qualitativo, em 2015/2016, dezenove professores de uma escola municipal, localizada no município de Niterói, Rio de Janeiro. Com relação aos instrumentos de pesquisa para o apanhado das informações, utilizamos questionários com questões fechadas e abertas e entrevistas semiestruturadas, além da observação dos espaços (escola e Fundação Municipal de Educação) para tentar fazer links entre a política e a prática de formação para os professores, propondo uma reflexão teórica e priorizando uma análise qualitativa. Em quase sua totalidade, os participantes relataram considerar sua formação inicial insuficiente para exercerem sua função. Percebemos aqui a necessidade de trocas e espaços formativos que fortaleçam os professores no sentido de valorizarem seus saberes desenvolvidos por meio de suas práticas diárias.

Palavras-chave: Formação docente; Formação continuada; Educação em tempo integral.

Abstract: The article reflects on the training of teachers working in a school that provides full-time education for the first five years of primary school, and on whether such training is sufficient to provide teachers with a more complete training with their participation in courses, lectures and training meetings, and continuing training in service. Thus, we offer some reflections on how these professionals perceive changes in their pedagogical practice. The main issue highlighted is: how does the continuing education offered by the municipal education system change (or not) the teacher's practice? Nineteen teachers at a municipal school, located in the city of Niterói, Rio de Janeiro, participated in this qualitative study. With regard to the research tools for gathering information, we used questionnaires with closed and open questions and semi-structured interviews, as well as observation of spaces (school and Municipal Education Foundation), in an attempt to make links between the policy and the practice of teaching training, proposing a theoretical reflection and prioritizing a qualitative analysis. Almost all the participants reported that their initial training was insufficient to perform their function. Here we notice the need for exchanges and formative spaces that will strengthen teachers, valuing their knowledge developed through their daily practices. 
Keywords: Teacher Training; Continuing education; Full-time education.

Resumen: El artículo ofrece la oportunidad de reflexionar sobre la formación de los docentes que trabajan en una escuela que imparte educación a tiempo completo durante los primeros cinco años de primaria y sobre si esa formación es suficiente para proporcionar a los profesores una formación más completa con su asistencia a cursos, conferencias y reuniones de formación y formación continua ofrecida durante su trabajo. Así, traeremos algunas notas sobre cómo estos profesionales perciben los cambios en su práctica pedagógica. Como tema principal, destacamos: ¿cómo la formación continua ofrecida por el sistema educativo municipal altera (o no) la práctica de los maestros? Diecinueve maestros de una escuela municipal, ubicada en la ciudad de Niterói, Río de Janeiro, han participado en el estudio cualitativo. En cuanto a las herramientas de investigación para la recopilación de información, se utilizaron cuestionarios con preguntas abiertas y cerradas y entrevistas semiestructuradas, así como la observación de espacios (escuela y Fundación de Educación Municipal) para tratar de vincular la política y la práctica docente, proponiendo una reflexión teórica y la priorización de un análisis cualitativo. En su casi totalidad los participantes informaron que su entrenamiento inicial era insuficiente para desempeñar su función. Aquí notamos la necesidad de intercambios y espacios formativos que fortalezcan a los docentes para valorar sus conocimientos desarrollados a través de sus prácticas cotidianas.

Palabras clave: Capacitación docente; Educación continua; Educación a tiempo completo.

\section{INTRODUÇÃO}

O artigo que ora apresentamos é fruto de um constante pensar e repensar nas políticas públicas educacionais e seus desdobramentos sobre o fazer (a prática) docente no cotidiano escolar, com o intuito de melhor compreender o desafio de participar da construção de um modelo escolar de uma rede municipal de educação, sendo necessário fazer o movimento de pesquisa que pudesse formar e ampliar o entendimento acerca das experiências anteriores, já consolidadas, e que trataram da questão da ampliação do tempo na escola. Entre as muitas possibilidades de temáticas a serem investigadas neste contexto de implantação de um modelo escolar diferenciado, elegemos como objeto de estudo a formação continuada dos docentes da referida escola. Então, nossas indagações vão na seguinte direção: qual a importância da formação continuada no processo de transformação da prática docente em uma escola de educação e $(m)$ tempo integral? Quais os benefícios que a formação continuada traz (ou não) para o docente que atua numa escola de tempo integral? Silva (2014, p. 25) aponta "[...] três premissas que utilizamos para pensar a formação do professor para a educação integral na escola de tempo integral: função da escola, função docente e trabalho docente [...]".

No decorrer de nossa investigação, pudemos aprofundar tais premissas ilustrando com dados quantitativo-qualitativos tais desdobramentos na prática por meio dos registros realizados com os resultados do capítulo de campo. Nosso objetivo geral foi analisar as percepções dos professores da escola pesquisada em relação à formação continuada oferecida pela rede municipal de Niterói/RJ.

Como desdobramento do objetivo geral, tivemos os seguintes objetivos específicos: analisar o ordenamento normativo que trata dos temas Educação em Tempo Integral e 
Formação Continuada do docente a partir da Lei de Diretrizes e Bases da Educação Nacional no 9394/96; Identificar as concepções que os docentes participantes da pesquisa têm sobre a formação continuada oferecida pela Rede de Educação do município de Niterói, para tanto, refletimos com Nóvoa (1995, p. 25): "A formação não se constrói por acumulação (de cursos, de conhecimentos ou de técnicas), mas, sim, através de um trabalho de reflexividade crítica sobre as práticas e de reconstrução permanente de uma identidade pessoal".

A formação de professores vem assumindo posição de destaque nas últimas décadas nas discussões relativas às políticas públicas, bem como nas investigações e nas publicações da área. O estudo da formação docente envolve um número considerável de autores, como Nóvoa (1991) e Huberman (2013), entre outros que evidenciam a insuficiência da formação inicial para o desenvolvimento profissional do professor e a necessidade de se levar em conta o saber que ele acumula tendo a escola como lócus de formação docente. Esse consenso põe em destaque a necessidade de pensarmos em uma formação continuada que valorize tanto a prática realizada pelos docentes no cotidiano escolar quanto o conhecimento que provém das pesquisas realizadas na universidade, de modo a articular teoria e prática na formação e na construção do conhecimento profissional do professor (BERNADO, 2003; 2015). Tendo essa perspectiva como pano de fundo, procuramos caracterizar a formação continuada de professores que acontece no lócus da pesquisa. Nessa perspectiva, o foco da pesquisa dirigiuse à formação continuada que acontece no interior da escola, nos diferentes momentos e instâncias em que há trocas entre professores e deles com outros profissionais da escola.

\section{Políticas de Formação Continuada: avanços e desafios}

O início do novo milênio trouxe à escola a promessa da educação para todos quando, de fato, o que houve foi a ampliação do acesso e da permanência dos alunos nas escolas, em uma busca incessante por melhoria dos índices na qualidade da educação. Nesse sentido, entendemos o aumento da oferta de cursos de formação continuada como recurso utilizado na busca por uma organização de saberes eleitos para compor e alcançar as metas estabelecidas pelas esferas governamentais, sejam estas municipal, estadual ou federal, em suas especificidades e demandas próprias ou até mesmo as metas conhecidas globalmente por estarem inseridas em uma agenda mundial e organizadas por agências internacionais. Segundo Monfredini (2008), a década de 1990 buscou a universalização no atendimento da população brasileira e, consequentemente, o aumento da permanência da população na escola, abrindo, assim, caminho para a implementação de políticas orientadas por organismos multilaterais que apresentavam suas ideias de educação atreladas ao desenvolvimento do país.

Nesse sentido, verificamos uma continuidade na implantação de um projeto educacional que, além do Brasil, engloba América Latina e Caribe, evidenciando um modelo elástico que entrelaça diferentes realidades sociais, políticas e educacionais, amarrando-as de forma a adequar as variadas demandas aos programas propostos (SHIROMA; EVANGELISTA, 2004, p.532). As autoras atentam que as orientações contidas em uma série de documentos específicos para América Latina e Caribe abordavam em seus textos a indicação de formações 
contínuas voltadas para os professores, incentivando-os a "participar das políticas educacionais formulando-as e executando-as; ser reflexivos, autônomos, criativos e comprometidos com a mudança" e indicando que tais formações deveriam alcançar o maior número de profissionais possíveis e, dessa forma, indicavam a modalidade a distância.

Com isso, o cenário que se delineou foi: propostas privatistas e do desinvestimento na educação pública, de modo geral, referente ao início da década de 1990, com as políticas neoliberais, discutindo e propondo a "profissionalização das ações educativas" (SHIROMA; EVANGELISTA, idem), ganhando fôlego as discussões de como formar o profissional da educação para realizar atividades e melhorando o uso dos recursos em atividades diretivas de formação continuada.

Consideramos que a lógica de formação ofertada por redes de ensino, secretarias de educação e pelo governo federal, é importante ferramenta de alcance do profissional docente, todavia, registramos aquelas formações organizadas dentro do espaço escolar, tendo a escola como lócus de formação continuada, como sendo possibilidade de crescimento do grupo e de troca efetiva entre os profissionais de cada unidade escolar. Essas formações não são novidade e, de acordo com Candau (2001, p. 52), a ênfase é posta na "reciclagem" dos professores. Como o próprio nome indica, "reciclar" significa "refazer o ciclo", voltar e atualizar a formação recebida e a autora esclarece que, em muitos casos, essa atualização se dá por conta de cursos em parcerias nas universidades, especializações e extensões, bem como cursos Lato Sensu e Stricto Sensu. E a autora continua afirmando que "Este tem sido o sistema habitual de formação continuada dos profissionais do magistério, sistema que ainda hoje, me atreveria a afirmar, é o mais frequente e comumente aceito e promovido" (CANDAU, 2001, p. 53).

As formações continuadas, em parceria com universidades, criaram um forte canal de diálogo, estabelecendo uma relação simbiótica bastante interessante. Por um lado, o professor entra em contato com o espaço acadêmico como profissional e aluno. Por outro lado, a academia ganha novas possibilidades de repensar a teoria a partir do contato com as práticas estabelecidas no espaço escolar.

Perrenoud (2002) destaca que a organização de formações contínuas se deu de maneira a complementar a formação de muitos professores com informações e estudos que eles não haviam recebido durante a formação inicial. Tais iniciativas ocorreram na Itália com título de "aggiornamento" e "recyclage", termo utilizado em algumas regiões da França. No Brasil, essa discussão tem início na década de 1990, tornando-se uma polêmica pela recusa dos cursos de "reciclagem" por parte dos professores, provocado pelo mal-estar que a categoria profissional tinha pelo termo cunhado para atualização. Ao mesmo tempo em que Candau (2001) nos traz o sentido de "retornar ao início do ciclo" ou "refazer o caminho das aprendizagens", por outro lado, os docentes repudiavam as nomenclaturas desses cursos por caracterizar algo que precisa de nova forma.

Perrenoud (2002) salienta ainda que, por muitos anos, a dinâmica utilizada nessas formações ocorreu sem levar em consideração a prática desenvolvida pelo profissional no dia a dia do espaço escolar. Não raro, temos os relatos desinteressados por parte dos profissionais que participavam destas formações, que saíam de seus lócus de trabalho para receber uma 
quantidade significativa de informações sobre novos métodos, técnicas e tecnologias para serem utilizados em suas salas de aula.

Insistir em políticas de formação continuada cada vez mais abrangentes é oportunizar discussões mais profundas e complexas acerca do trabalho docente. Contreras (2002, p. 155) afirma que "Muitos professores, em virtude das características da instituição educacional e da forma pela qual nela se socializam, tendem a limitar seu universo de ação e de reflexão à sala de aula". Segundo o autor, esses espaços de formação continuada necessitam de uma nova organização, que propiciem "[...] uma compreensão teórica sobre aqueles elementos que condicionam sua prática profissional, mas dos quais pode não ter consciência." (CONTRERAS, 2002, p. 155). Ainda sobre este tema, Perrenoud (2002, p. 23) destaca a importância destas formações transformarem-se "[...] progressivamente em laboratório de procedimentos de formação em prática reflexiva".

Se a oferta de cursos e/ou políticas de formação continuada mantiver seu olhar sobre o docente como apenas um agente cumpridor de protocolos, aplicador de avaliações, reprodutor de conceitos e métodos e práticas não reflexivas, então esse processo formativo de nada valerá na transformação da prática docente e da atuação desse profissional no cotidiano escolar.

\section{Metodologia}

Optamos por utilizar em nosso estudo a abordagem qualitativa e concordamos com a definição de Gardini $(1997$, p. 6) por compreender que a expressão pesquisa adota um novo sentido:

Passando a ser concebido como uma trajetória circular em torno do que se deseja compreender, não se preocupando única e/ou aprioristicamente com princípios, leis e generalizações, estando centrado em afinar o olhar para que os elementos se destaquem por seus significados explicitados no contexto da pesquisa.

Para o desenvolvimento deste estudo, contamos com as pesquisas bibliográfica e documental quanto aos ordenamentos específicos que abrangem as temáticas de tempo integral e formação continuada docente, buscando dialogar com a LDBEN nº 9394/96, bem como com as Diretrizes Curriculares Nacionais que tratam de formação docente. Após a construção do arcabouço teórico deste trabalho, analisaremos tais informações elegendo como metodologia o estudo de caso.

Dessa forma, compreendendo que o lócus de investigação é espaço único e com características próprias de uma escola com uma proposta experimental na rede municipal de educação de Niterói e que o sujeito de pesquisa é o professor que desenvolve seu fazer profissional nesse espaço diferenciado em diversos aspectos (horário, currículo, formação, planejamento) e no intuito de conjugar as leituras referenciadas e o ordenamento legal em consonância com os dados qualitativos e quantitativos, propomos desenvolver o levantamento dos dados do campo com as leituras específicas das temáticas de educação em tempo integral e formação continuada docente.

O estudo foi aprovado pela Comissão Científica em 2016, sob número 1.700/763 e do Comitê de Ética da UNIRIO (CEP) sob número 55797416.4.0000.5285, contando com o Termo 
de Consentimento Livre e Esclarecido (TCLE) e respeitando os aspectos éticos de pesquisas com pessoas.

\section{Resultados}

Aqui apresentaremos os destaques emergidos do campo de nossa pesquisa, as falas dos participantes com relação à compreensão que eles apresentaram sobre a formação continuada e como essa formação continuada, em serviço ou não, impacta a sua prática na escola de tempo integral.

\section{Situando a proposta de Formação Continuada e Educação INTEgRAL EM Tempo Integral EM Niterói/RJ}

A Rede Municipal de Educação de Niterói apresenta em sua estrutura uma formação composta por Secretaria Municipal de Educação, Ciência e Tecnologia e Fundação Municipal de Educação, sendo a mantenedora da educação em Niterói, e uma autarquia com autonomia financeira e administrativa realizando a gestão direta dos recursos da educação, além de ser responsável pela gestão pedagógica de toda a rede. Segundo Pustiglione (2014, p. 76),

A Fundação Pública Municipal de Educação de Niterói surge em 1991, através do Decreto n 6.172, publicado em 20 de agosto de 1991, em conformidade com o item VI do artigo 66 da Lei Orgânica Municipal e autorizado pela Câmara dos Vereadores sob a Lei n ${ }^{\circ} 924$ de 15 de janeiro de 1991. Outro documento importante que auxiliou nossas análises - publicado à mesma época e em consequência dos dois anteriormente citados - é o Regimento Interno da FME, instituído através do Decreto 6.303 de fevereiro de 1992.

A rede municipal de Niterói apresenta uma expansão contínua de suas unidades escolares de educação infantil e fundamental I. Assim, as Unidades Municipais de Educação Infantil (UMEIs) foram gradativamente aderindo ao horário integral, funcionando de $8 \mathrm{~h}$ às $17 \mathrm{~h}$. Com base neste modelo, em 2013, foi organizada uma comissão para elaborar uma proposta de Educação em Tempo Integral para o Ensino Fundamental. Essa comissão recebeu o nome de "Dacio Tavares Lobo Júnior"

Em 2014, amparada pelos estudos e discussões realizados durante todo o ano de 2013, a Rede Municipal de Educação de Niterói colocou em prática a proposta construída no ano anterior. No início do ano de 2014, foi estabelecido um calendário de quatro fóruns que deveriam ocorrer ao longo do período letivo com a participação de diferentes atores envolvidos na implantação do tempo integral.

A comissão ainda avançou na discussão sobre a organização do tempo e do currículo de disciplinas que seria integrada às escolas participantes deste momento inicial de educação em tempo integral. Fez-se necessário pensar na organização do tempo neste espaço escolar. Assim, destacamos trecho do documento elaborado pela Comissão que aborda a proposta como sendo de "Tempo Integral":

Pensar uma proposta curricular em tempo integral implica um esforço renovado de buscar outras e, quem sabe, novas alternativas para organizar os tempos, os espaços e as atividades a serem desenvolvidas no 
cotidiano escolar, visando proporcionar experiências variadas de aprendizagem que tenham um caráter desafiador, significativo e prazeroso. (NITERÓI, 2013 p. 31).

Em consonância com o texto anterior, citamos a fala de um entrevistado que participou da Comissão responsável pela proposta de tempo integral em Niterói.

\begin{abstract}
Então, essa proposta, eu lembro que no ano de 2014, ela seria testada, e aí já tínhamos três escolas na ocasião, que era o Demenciano, o Anísio Teixeira, que já tinha sido inaugurado com essa proposta, e a Elvira que tinha se transformado. Então, ao longo de 2014, era para se discutir mesmo quais são os limites do currículo, que a gente havia pensado inicialmente, do tempo de planejamento, dos horários de planejamento individual [...]. (Entrevistado 1).
\end{abstract}

Os participantes da Comissão responsável pela elaboração da proposta de educação em tempo integral organizaram uma Matriz Curricular com vistas a propiciar aos alunos experiências plenas de sentido de sua formação cidadã, cognitiva, afetiva e social. A seguir, faremos a apresentação do lócus desta pesquisa, realizada na Escola Municipal Anísio Teixeira. Ela se localiza no bairro de São Domingos, local de fácil acesso, urbanizado, próximo ao grande centro comercial da cidade.

A unidade escolar foi inaugurada em março de 2014 e seu funcionamento ocorre das $8 \mathrm{~h}$ às $17 \mathrm{~h}$, o diferencial da escola está na organização curricular. A escola iniciou seu funcionamento com 225 alunos distribuídos em nove turmas do primeiro e segundo ciclos do ensino fundamental. Todos os alunos, funcionários, equipe pedagógica e direção começaram a escola junto com sua própria história, entretanto, o quadro funcional sofreu modificações por motivos variados, tais como aposentadoria, licença especial, licença maternidade, não adaptação à proposta escolar e afastamentos por motivos de saúde/readaptação.

O quadro profissional da escola é composto por uma equipe denominada Equipe de Articulação Pedagógica (EAP), abarcando as funções de Diretor Geral e Adjunto e Pedagogos. $\mathrm{Na}$ unidade escolar, atuam como docentes professores generalistas em regime de 40 horas; professores de apoio especializado, que atendem crianças com necessidades educacionais especiais; professores de áreas específicas (educação física, artes plásticas, música, língua francesa); professor articulador; e professores de sala de recursos. Outros membros que completam o quadro funcional da unidade escolar são: secretária escolar, agente administrativo, cozinheiros, pessoal de apoio da Companhia de Limpeza Urbana de Niterói, Coordenadores de turno e auxiliar de portaria.

O prédio está construído totalmente na horizontal, facilitando a rotina de rodízio de salas e a mobilidade dos alunos com necessidades educacionais especiais. Em relação às salas de aula, elas são divididas em dois tipos: salas base e salas ambientes. Os alunos trocam de sala, no mínimo, três vezes por dia; e os professores devem planejar levando em consideração a Matriz Curricular e o espaço físico, o qual proporciona que os referidos alunos estejam em constante contato com vários ambientes a cada momento do dia.

Em relação ao período de formação e à sua forma organizacional dentro desta rede de educação, apontamos que, em relação ao horário de atendimento do aluno, este apresenta um diferencial às quartas-feiras devido ao horário coletivo de planejamento dos professores ${ }^{2}$, o qual é também destinado aos encontros de planejamento e formação continuada dos professores. 
É um momento de estabelecer uma rede de trocas e interações entre os professores e os profissionais que atuam na escola.

Neste sentido, de acordo com a Portaria n. 87 de 2011, na Rede Municipal de Educação de Niterói o tempo para a formação continuada obedece à seguinte organização:

Art. 22: As reuniões semanais de avaliação e planejamento devem ser de caráter informativo, organizacional, reflexivo e avaliativo, com foco na elaboração, implementação e acompanhamento do Projeto Político-Pedagógico, do Plano de Ação Anual e do Plano de Trabalho do Ciclo, bem como na formação continuada dos profissionais da Unidade de Educação.

Após este breve histórico com vistas a situar o leitor em relação ao espaço onde desenvolvemos nossa pesquisa, entraremos no foco de nosso texto, o professor e a formação continuada em uma escola de educação integral em tempo integral.

A Portaria n. 87 de 2011 estabelece a forma como o tempo deve ser utilizado nestas reuniões semanais, ou seja, a finalidade de informes, análise e avaliação do andamento do trabalho pedagógico, como também aponta para um espaço de formação continuada. Cabral (2015, p. 251) destaca:

O quanto é importante para elaboração e realização da formação continuada considerar os professores como profissionais que se formam num trabalho coletivo que tenha como foco refletir sobre seus próprios percursos e também conhecer a escola como um lugar onde os professores, ao mesmo tempo aprendem com o desenvolvimento de suas rotinas diárias, produzem novos conhecimentos pedagógicos.

Garantir o espaço no currículo de toda a rede municipal para estimular o crescimento profissional faz toda a diferença no olhar que se lança sobre a organização da estrutura escolar. Candau (1997) destaca a importância de utilizar a escola como o lócus de formação continuada. Bragança e Perez (2016, p. 1169) indicam que "[...] tomar a reflexão sobre a prática como o principal objetivo da formação continuada, implica assumir a centralidade da escola como espaço de construção cotidiana de saberes docentes." Esta centralidade da formação continuada tem se mostrado um grande desafio a ser superado na organização das escolas de tempo integral.

\section{Ciclo profissional docente: alguns apontamentos}

A pesquisa partiu da seguinte estratégia: um questionário com itens com respostas abertas ou fechadas entregues, pessoalmente, a 33 (trinta e três) professores da escola, entre eles: regentes, professores de apoio especializado (que atendem alunos com necessidades educacionais especiais), professor de sala de recursos e professores em desvio de função (exercendo cargo de coordenação de turno) ou readaptados e professores de áreas específicas (música, francês, artes plásticas, educação física). Deste universo, retornaram respondidos 19 (dezenove) questionários.

Sua organização foi composta por duas partes: a primeira trazia os dados demográficos: idade, gênero, formação (nível médio/normal, superior, normal/superior) e a segunda parte abordava a avaliação dos profissionais quanto à satisfação do local em que trabalha, da carga horária semanal e do interesse em relação à formação continuada oferecida por cursos do 
governo (MEC, CAPES), por cursos oferecidos pela Fundação Municipal de Educação do referido município e pelo interesse do profissional em participar de formações continuadas em serviço.

Com relação ao sexo dos professores respondentes, cinco são do sexo masculino e catorze do sexo feminino. Em relação à faixa etária, um professor se encontra na faixa etária até 24 anos; dois estão entre 25 aos 29 anos; oito, na faixa dos 30 aos 39; quatro, na faixa etária dos 40 aos 49 anos; um, entre 50 e 54 anos; dois, acima dos 55 anos de idade e um professor não respondeu esta questão.

A questão que abordava a experiência profissional nos remete também não só ao tempo de exercício do magistério, mas ao vínculo desse profissional com a rede pública de Niterói. Podemos perceber que a quantidade de professores concursados (11) e contratados (8) é muito próxima, o que nos remete a refletir sobre a meta 18 do PNE, na qual há a preocupação de haver, até $2017,90 \%$ do quadro funcional dos profissionais da educação básica regido pelo estatuto de servidores públicos concursados.

No item tempo de experiência docente, utilizamos a organização de Huberman (2013), que classifica em cinco estágios o momento do ciclo profissional do docente, mas reconhece e ressalta que essa organização é flexível, não devendo ser tomada como uma visão estática e linear. De acordo com os estudos de Huberman (2013), a carreira docente acompanha um ciclo de vida profissional, cujo autor divide da seguinte forma: os primeiros 3 anos na carreira: entrada/tateamento; entre 4 e 6 anos: estabilização, consolidação de um repertório pedagógico; entre 7 e 25 anos: ativismo, diversificação/questionamentos. Entre os 25 e 35 anos na profissão: serenidade e distanciamento afetivo. Entre os 35 e 40 anos na profissão: o momento do "desinvestimento", que, no entender do autor, pode seguir duas vias (sereno ou amargo). Candau (2001, p.63) destaca que "os problemas, as buscas dos professores não são as mesmas nos diferentes momentos do seu exercício profissional e que muitos dos esquemas de formação continuada ignoram este fato". A autora aponta ainda para o fato de os cursos ofertados serem os mesmos para os profissionais em diferentes etapas da carreira.

Segundo os dados coletados, o grupo que respondeu o questionário estaria dividido basicamente em dois grandes grupos, a saber: um quantitativo, que se encontrava na fase da estabilização e da consolidação de um repertório pedagógico (entre 4 e 6 anos), e um segundo grupo que se encontra enfrentando o momento de ativismo, mas também de questionamento (entre 7 e 25 anos). Com esses dois blocos etários, é possível perceber as diferenças de interesses. Enquanto um grupo vive a consolidação do fazer pedagógico, outro grupo se situa no momento de lutas e no ativismo na profissão.

Sobre a formação para exercer o magistério, de nove professores das séries iniciais que têm como primeira habilitação para o exercício do magistério o curso de Formação de Professores em Nível médio, seis buscaram continuar sua formação por meio do curso superior em Pedagogia, dentre os quais, cinco cursaram cursos de especialização na modalidade Lato Sensu. Os outros dez profissionais dividiram-se em dois grupos: o primeiro composto por seis professores que cursaram Pedagogia e o segundo grupo com quatro professores que cursaram áreas diversas (Letras, Educação Física, Música, Artes). 
A formação continuada vem se tornando uma política de estímulo na carreira como forma de progressão salarial, deste modo, a busca por um aperfeiçoamento lato e strictu sensu vem aumentando a cada ano, independente da modalidade ser presencial ou a distância.

A busca por continuidade nos estudos revela ainda o anseio por estar "atualizado" para concorrer às vagas públicas, realizando assim o desejo de efetivação por meio de concurso. No tópico que buscava evidenciar o vínculo do profissional com a rede municipal de educação, dos 19 respondentes, 11 ingressaram via concurso e 8 estão em situação de contrato temporário. Este fenômeno da terceirização vem de encontro às discussões sobre valorização profissional do magistério e da luta por condições de trabalho condizentes com a função.

Os dados qualitativos dos questionários revelaram uma dificuldade em dissociar e reconhecer as diferenças existentes entre Tempo Integral (quantitativo de horas em que o aluno passa na escola) e Educação Integral (preocupação com a formação mais completa do aluno, abrangendo aspectos cognitivos, esportivos, culturais, de cidadania, de construção de hábitos saudáveis, entre outros).

As falas recorrentes que interligavam a educação integral ao "educar com amor" (Professor 1), "substituir a ausência de carinho que os alunos carregam" (Professor 15), "fazer o papel da família" (Professor 6), apontam uma falta de clareza em relação ao exercício da função profissional, independente do quantitativo de horas em que o aluno permaneça na escola. Maia (2009, p. 119) destaca a importância do trinômio "amor-dedicação-vocação" como uma marca relacionada à identidade docente com relação ao feminino, à vocação e às habilidades moral e intelectual recebidas no interior do lar.

Isso reforça uma lógica que vem se instalando nas escolas de tempo integral, que é o espaço do cuidar se sobrepondo ao espaço da construção de conhecimentos diversos. Não podemos deixar de perceber que, com a permanência ampliada dos alunos no espaço escolar, observamos questões que possivelmente ficariam invisíveis em uma escola de tempo parcial. Assim, o aumento da permanência do aluno na escola por meio do horário integral traz à tona dificuldades e possibilidades/potencialidades do aluno, que podem ser trabalhadas e encaminhadas para outros espaços, a fim de auxiliar sua formação. Uma fala que marca essa compreensão omnilateral é descrita na seguinte narrativa: "Educação Integral diz respeito à integralidade do sujeito, ou seja, trabalhar o ser humano em todas as suas dimensões: afetividade, valores, saúde, corpo, cultura etc. Na educação Integral, todos os espaços precisam ser de aprendizagem e os conteúdos trabalhados de forma conectada à realidade do educando e de forma ampla, fluída e permanente". (Professor 2).

Outro professor também avança na compreensão da educação integral, sinalizando a importância do(s) espaço(s): "É uma educação que engloba várias práticas educacionais, que não fique presa dentro de uma sala de aula." (Professor 4)

Complementando a visão do professor anterior e ampliando a discussão, a próxima fala abrange a temática da educação integral na perspectiva da proteção social. "Bem, acho que a escola integral é o espaço para o desenvolvimento nas múltiplas áreas de aprendizagem. Além disso, também é uma forma de manter as crianças fora das ruas, ocupadas com atividades direcionadas". (Professor 5) 
Quando Paro (2009, p.13) afirma que ou a "[...] educação é integral ou não é educação", ele ressalta que toda educação deve primar pela potencialização do desenvolvimento do indivíduo. Não é a questão do tempo na escola para favorecer os cuidados com os alunos (isto também é muito importante), mas, ao contrário, ele considera que estar na escola tem que favorecer um tempo de qualidade no trabalho pedagógico desenvolvido.

Levantando a questão de que, independente da forma organizacional, a educação precisa ser plena e levar os alunos não só a ler e escrever, mas a gostar de ler e escrever, a perceber nessas práticas ferramentas para modificação de sua situação, melhoria em sua qualidade de vida, alavanca para um futuro de realização pessoal, profissional.

Quando perguntados sobre o que é o Tempo Integral, obtivemos as seguintes percepções: "Tempo integral seria a ampliação da carga horária, onde o aluno passaria mais tempo na escola o que ampliaria as oportunidades de vivência." (Professor 11), "Tempo integral abrange todo o período de contato com o aluno, em qualquer espaço físico, dentro ou fora da instituição escolar." (Professor 19), "Tempo em que a criança permanece na escola em atividades desenvolvidas para ela." (Professor 10), "No nosso caso, 9 horas." (Professor 17), "É um horário estendido para o desenvolvimento de diversas atividades educativas." (Professor 7), Uma jornada de tempo ampliada na escola." (Professor 8), "Vejo esse tempo integral como o tempo que os alunos teriam ociosos em casa ou nas ruas. Preencher esse tempo integral com educação é fundamental." (Professor 9).

Com relação à compreensão de tempo integral, além de não ser consenso, é particular a cada profissional. Uns veem no aumento do tempo a oportunidade de melhorar a condição social do aluno, retirá-lo do risco de estar nas ruas. Outros já apontam que é todo o tempo em que se está em contato com o aluno, independente do espaço físico, há quem aponte o Cronos como regulador dessa relação e ainda temos uma fala que pedagogiza o tempo, por meio da aplicabilidade de atividades durante o período em que o aluno está na escola. Um professor faz um apontamento interessante ao se referir ao tempo integral como "Horário comercial" (Professor 5), revelando, assim, a organização do tempo da escola de acordo com a organização do tempo do trabalho dos responsáveis, ou seja, a escola se organizando para atender às demandas da sociedade.

Dessa forma, podemos perceber alguns desafios no desenvolvimento da proposta, apontados pelos professores: infraestrutura para as aulas específicas (música, teatro, sala de leitura/biblioteca), pessoais: adequação a uma proposta diferenciada de tempo, organização curricular e dinâmica proposta pela escola, entre outros.

Com tais excertos, evidenciamos três aspectos que gostaríamos de ressaltar: a necessidade contínua de novas discussões sobre a proposta de tempo integral no município de Niterói e, principalmente, sua organização na unidade escolar; a questão de falta de material apropriado e pouco espaço físico para determinadas atividades (a escola não dispõe de uma sala para aulas de música, biblioteca ou auditório, apesar de ter em sua estrutura alguns espaços que podem e são utilizados para cumprir a matriz destas atividades); por fim, explicita-se nas falas dos professores a necessidade de aprofundar e refletir acerca de suas práticas. Chinelli (2015) enfatiza que o movimento de reflexão tão difundido na área da formação docente, em 
vez de impulsionar autonomia para o profissional, tem levado os profissionais a uma maior preocupação na reprodução de elementos curriculares de maneira eficiente, aumentando a lacuna entre o saber construído na academia e as práticas experienciadas na escola.

Hargreaves (2014) afirma que o tempo estrutura o trabalho docente e vice-versa e que é uma relação simbiótica. E na proposta de educação em tempo integral esta relação ganha um peso ainda maior. Dessa forma, é inevitável fazer alguns apontamentos acerca do tempo do professor.

No referido município, a regulamentação do horário de planejamento do professor, de acordo com a Lei n. 11.738 de 2008, ao instituir 1/3 do horário de trabalho para planejamento, gerou um grande nó nas escolas. Quando perguntados sobre o tempo integral, os professores apresentaram as seguintes respostas: "tempo a mais para o aluno aprender" (Professor 1); "maior tempo para os pais ficarem tranquilos trabalhando" (Professor 12); "tempo para o aluno ser cuidado e receber uma alimentação balanceada" (Professor 8).

Bragança e Perez (2016, p. 1165) fazem uma releitura dos tempos de Hargreaves (2014) sobre esta divisão micropolítica que envolve os diferentes tempos do dia a dia da escola, em especial, enfatizando tal aspecto na escola de tempo integral.

A amplitude da discussão tempo-sujeitos-integralidade dificilmente será objeto de congruência e consenso. Passamos agora em nossa pesquisa a refletir sobre nossas percepções sobre o caminho que percorremos ao longo deste processo de leitura, reflexão, imersão no campo, releituras, diálogos, as quais contribuíram para chegarmos ao eixo motivador deste trabalho. Afinal, desejamos analisar as percepções dos professores em relação à formação continuada oferecida pela rede municipal de educação com vistas ao fortalecimento da educação em tempo integral em Niterói/RJ.

Observando os dados, vemos que o professor se sente contemplado com as formações continuadas na unidade escolar, sendo este o item que alcança as maiores notas em termos de satisfação. Podemos inferir que o fato de o professor regente e o professor de apoio especializado permanecerem na mesma escola o dia todo pode ser um facilitador para participar de atividades específicas e organizar melhor seu tempo.

Em relação à participação em atividades de formação continuada, vemos que o incentivo maior é de iniciativa da gestão da unidade escolar e, na avaliação dos professores, ocorre com menos frequência por parte da Fundação Municipal de Educação.

Quando perguntado sobre a formação continuada ocorrida na escola, temos o seguinte relato: "O fato de já estar no local de trabalho ajuda. Nos sentimos mais à vontade para falar, tirar dúvidas. Quando é em outro local, não gosto de falar. Fico só ouvindo. Muitas vezes, não me diz nada." (Professor 4).

Outro participante relata: "Acho bom quando é fora da escola, assim a gente vê gente diferente, ouve coisas novas. Mas nas formações dentro da escola podemos ver nossas necessidades, pois não é fácil trabalhar no mesmo lugar, todos os dias o dia todo. As crianças ficam muito próximas, ficam com a gente o tempo todo". (Professor 3).

Candau (2001) relata que a Universidade tem sido o lócus eleito para as reciclagens ou as atualizações formativas dos professores por meio de convênios e parcerias. Entretanto, 
apesar da importância que esta troca favorece, a autora percebeu em seus estudos que isso não revela uma ação com efeito direto na prática do professor na escola.

Tardiff (2002) apresenta esses saberes como experienciais, que ultrapassam as "receitas de bolo" que muito pouco modificam o fazer e o ser do profissional docente. Com efeito, os processos formativos atuais necessitam atingir dois objetivos: favorecer a melhoria na formação do profissional e proporcionar o avanço dos contextos que cercam este profissional. O autor destaca a importância das formações continuadas como forma de preenchimento do professor que, ao partilhar com seus pares, esvazia-se para novamente completar-se. Neste sentido, Vasconcellos e Bernado (2016, p.215) destacam:

Entendemos que, se a oferta de formação continuada mantiver seu olhar sobre o docente como um agente "cumpridor de protocolos", "aplicador de avaliações", reprodutor de conceitos e métodos e práticas não reflexivas, então esse processo formativo de nada valerá na transformação da prática docente e da atuação desse sujeito, desse profissional no cotidiano escolar.

Trazemos, então, a seguinte reflexão: O professor da escola de tempo integral precisa de mais tempo de formação e a escola precisa de maior quantidade de professores que possam cobrir aqueles que estão em formação. Quanto à formação coletiva, como equacionar a necessidade de o aluno estar na escola? Essas questões necessitam de muitas reflexões, novas escutas, tentativas e experimentações. O ponto é: ambos são sujeitos de direito à formação integral, o aluno e o professor. Bragança e Perez (2016, p. 1165) destacam a importância da formação permanente por ser "um conjunto amplo de ações que tem como intencionalidade a construção/reconstrução de saberes-práticas pelos professores/as".

É sem dúvida um grande desafio a oferta de formação continuada que atenda às demandas atuais, tornando-se mais complexa ao direcionar a questão pelo viés da oferta de educação integral e/ou tempo integral, visto que, conforme ressaltado anteriormente, na atualidade, a questão da terceirização do trabalho docente precisa ser discutida de forma séria e organizada. Há uma política de avaliação e um ranking do trabalho do professor, os quais urgem uma discussão mais detalhada, e que não é o foco deste trabalho.

\section{ReFLEXÕES FINAIS}

Os dados levantados revelaram as seguintes percepções: a educação básica nos anos iniciais ainda é uma área feminina em sua grande maioria; existe um mix de profissionais recém-formados com outros que já estão há mais de dez anos no exercício da profissão. Dentre os participantes da pesquisa, parte expressiva cursou o ensino superior, mesmo aqueles que já haviam obtido a habilitação para o magistério na modalidade normal. Explicitaram em suas falas que a busca por aprimorar e aprofundar a formação profissional com cursos e titulações, em geral, deve-se ao plano de carreira, que aumenta seus vencimentos de acordo com a formação obtida.

Em quase sua totalidade, os participantes relataram considerar sua formação inicial insuficiente para exercerem sua função. Percebemos aqui a necessidade de trocas e espaços formativos que fortaleçam os professores no sentido de valorizarem seus saberes desenvolvidos por meio de suas práticas diárias. 
Entre os desafios do cotidiano escolar, muitos sinalizaram a falta de interesse e de participação por parte dos pais, falta de tempo para atender às demandas do cotidiano escolar, um ambiente barulhento e questões de indisciplina que acabam "roubando" o tempo de aula. Contreras (2002) traz este apontamento do aumento de funções da carreira docente, extrapolando os limites da sala de aula.

As diferenças entre formação em serviço e planejamento são bem-estruturadas e claras nas falas dos docentes. São momentos separados e importantes de mesmo modo.

Salientamos a importância que aparecem tanto nas falas dos entrevistados como nas falas dos participantes que responderam ao questionário. Pudemos verificar proximidade nas percepções dos dois grupos, demonstrando que suas visões se permeiam e perpassam quando a temática formação continuada é discutida.

É consenso que o professor necessita estar em constante atividade formativa, entretanto, o questionamento é se somente esta maneira de cursos prontos atinge os objetivos do profissional.

Destacamos ainda que a política de terceirização, via contratos temporários, enfraquece a identidade do profissional, bem como não garante a efetivação deste professor no quadro funcional permanente da rede. É um investimento provisório e pouco eficaz. Com isso, não defendemos que os profissionais contratados não tenham acesso às formações oferecidas, mas atentamos ao fato de estar se fortalecendo uma política de incerteza ao não buscar por meio de concurso suprir as necessidades funcionais da rede municipal de Niterói.

Nossa pesquisa atentou para a importância de construir e implementar políticas públicas que valorizem e potencializem projetos educacionais de qualidade e voltados à formação integral, completa e complexa de alunos, e que também focalizem o fortalecimento da carreira dos profissionais da educação.

Vimos nas respostas dos professores uma variedade de percepções rica sobre o entendimento de tempo integral e educação integral. As falas nos remetem à outra visão: a do professor que não possui oportunidade para, em conjunto, travar estes diálogos formativos com seus pares. A impossibilidade de oportunidades de troca com os que estão no mesmo espaço deveria ser olhada com mais atenção pelos gestores e coordenadores para que as formações continuadas ganhassem força, forma e sentido para quem delas participa.

Apesar do tom dúbio em relação a sair da escola para poder participar de cursos e palestras, o dado que se verifica nesta fala nos parece a necessidade de trocar de ambiente. Ao mesmo tempo em que outro participante revela estar mais à vontade quando as formações ocorrem na escola, pois pode perguntar sem receio e participar mais ativamente.

Fato é que o grande diferencial da formação continuada para o docente é: faz sentido? Contribui para minha formação como sujeito? Afeta minha prática diária, me transforma em um melhor profissional?

Quanto ao trabalho pedagógico desenvolvido, percebemos que a grande maioria dos professores está satisfeita com a forma de trabalho proposta pela escola.

Nesses discursos, o que se torna perceptível é a noção de conhecimento em construção. Mesmo com uma formação sólida e anos de prática, os professores revelam, em sua grande 
maioria, a necessidade de buscar apoio pedagógico, recursos de mídias e tecnologias que auxiliem a trabalhar com estes alunos.

Destacamos ainda que professores que participam como cursistas do Pacto Nacional de Alfabetização na Idade Certa (PNAIC) ou como supervisores do Programa Institucional de Bolsas de Iniciação à Docência (PIBID) enfatizam que, participar coletivamente de formações acrescenta novas ideias para as práticas que desenvolvem em sala de aula, as quais, de forma geral, contemplam algumas lacunas formativas por meio da participação nestes cursos. Também revelaram que a bolsa recebida pela participação é um incentivo a mais. Sentem-se reconhecidos e valorizados pelo apoio financeiro.

Em relação ao trabalho na escola de tempo integral, os participantes apontaram a necessidade de um maior tempo para construir seu planejamento, o desgaste de estar no ambiente escolar por nove horas diárias, a falta de materiais que, desde 2015, vêm sofrendo cortes.

Apontaram, ainda, nas respostas fornecidas via questionário, para a necessidade de maior quantidade de profissionais para atender ao dia a dia da escola, pois o quantitativo atual se mostrou insuficiente.

Com relação a como percebem sua prática na escola de tempo integral, nenhum dos dezenove participantes atribuiu a si mesmo o conceito "excelente", como também não houve marcações no conceito "ruim/péssima". Em geral, situaram-se entre muito boa e em processo de aprendizagem.

Um importante fato que foi trazido em alguns questionários relaciona a quantidade de turmas com a proposta da escola. Segundo cinco participantes, o segundo ano da escola foi o melhor, dado o quantitativo de grupos de referência/número de alunos por turma.

Os participantes também revelaram insatisfação na questão de instabilidade na carreira e o desejo de um concurso para dedicação exclusiva em regime de 40h, com tempo para planejar e fazer cursos fora da escola. Assim, retomamos o pensamento de Hargreaves (2014) e sua reflexão sobre a necessidade de uma nova forma de organizar o tempo do professor, este tempo micropolítico, reducionista que, muitas vezes, desperta a percepção de solidão em seu fazer pedagógico (NÓVOA, 2002). Destacamos, então, a relevância de desenvolver novas práticas que conectem o professor ao outro, ao par, aumentando as possibilidades de trocas efetivas e constituintes de novos saberes.

Revelaram preocupação com o que fazer para que o tempo do aluno seja bem aproveitado na formação mais ampla, plena dele. Outras falas dão conta de uma preocupação no sentido de um olhar mais atento com crianças que não se adaptam à escola de tempo integral e, para as quais, esse tempo é de cansaço e até certo sofrimento.

Os professores enfatizaram nos questionários preocupação com os rumos da educação em tempo integral no município de Niterói, lembrando que, desde 2014, não ocorreram novos encontros formativos, sendo assim, descrevem que seria uma perda para a educação o fim da Escola Municipal Anísio Teixeira nos moldes em que ela se constituiu.

Por fim, trouxemos dados e falas dos participantes e dos entrevistados da pesquisa que forneceram um panorama instigante e que merece ser aprofundado com mais detalhe em pesquisas futuras. 
BERNADO, E. S. Formação continuada de professor em escolas organizadas em ciclo.106 f. Dissertação (Mestrado em Educação) - Programa de Pós-Graduação em Educação, Pontifícia Universidade Católica do Rio de Janeiro, Rio de Janeiro, 2003.

BERNADO, E. S. Formação docente: que tipo de profissional formar? Boletim Técnico do Senac, Rio de Janeiro, v. 41, p. 90-109, 2015.

BRAGANÇA, I. F. S. Espaçostempos no trabalho docente: narrativas de professoras. In: VELLOSO, L. M. Tempos e Espaços Escolares: Experiências políticas e debates no Brasil e no mundo. Rio de Janeiro: Faperj, 2014. p.99

BRAGANÇA, I. F. S.; PEREZ, J. G. Formação Continuada em Escolas de Tempo Integral: narrativas de professoras. Educação \& Realidade, Porto Alegre, v. 41, n. 4, p. 1161-1182, out./dez. 2016.http://dx.doi. org/10.1590/2175-623660612

BRASIL. Decreto N. ${ }^{0}$ 6.755, de 29 de janeiro de 2009. Institui a Política Nacional de Formação de Profissionais do Magistério da Educação Básica, disciplina a atuação da Coordenação de Aperfeiçoamento de Pessoal de Nível Superior - CAPES no fomento a programas de formação inicial e continuada, e dá outras providências. Diário Oficial da União, Brasília, DF, 29 de janeiro de 2009.

BRASIL. Lei No 9.394, de 20 de dezembro de 1996. Estabelece as diretrizes e bases da educação nacional. Diário Oficial da União, Brasília, DF, 23 dez. 1996. Disponível em: <http://www.planalto.gov.br/ CCIVIL_03/leis/L9394.htm>. Acesso em: 15 jul. 2015.

BRASIL. Parecer No 02 do CNE/CP, de 09 de junho de 2015. Dispõe sobre Diretrizes Curriculares Nacionais para a Formação Inicial e Continuada dos Profissionais do Magistério da Educação Básica, Brasília, DF, Resolução CNE/CP 2/2015. Diário Oficial da União, Brasília, 2 de julho de 2015 - Seção 1 - pp. 8-12. Disponível em: http://www.cref14.org.br/boletin/res_cne_cp_002_03072015.pdf.

CANDAU, V. M. Formação continuada dos professores: Tendências atuais. In: CANDAU, V. M. Magistério Construção Cotidiana. Petrópolis, RJ: Vozes, 2001 51-68.

CHINELLI, M. V. O sentido da formação de professores desenvolvida em parceria com escolas de educação básica. Nova Iguaçu: Entorno, 2015.

CONTRERAS, J. Autonomia de professores: os valores da profissionalização e a profissionalidade docente. São Paulo: Cortez, 2002.

GARNICA, A. V. M. Algumas notas sobre pesquisa qualitativa e fenomenologia. Revista: Interface - Comunicação, Saúde, Educação. Interface (Botucatu) vol.1 no.1. Botucatu. Agosto. 1997 - http://dx.doi. org/10.1590/S1414-32831997000200008. On-line version ISSN 1807-5762.

HARGREAVES, A. A política do tempo e do espaço no trabalho dos professores. In: MAURÍCIO. L. V. (Org.). Tempos e espaços escolares: experiências, políticas e debates no Brasil e no mundo. 1. ed. Rio de Janeiro: Ponteio/Faperj - 2014 (p.55-88).

HUBERMAN, M. O Ciclo de vida profissional dos professores. In: Nóvoa, A (Org.). Vidas de professores. Porto: Porto, 1995. P. 31-61

MONFREDINI, I. Profissão docente na instituição escolar: a historicidade das práticas e culturas profissionais. Educar, Curitiba, n. 31, p. 191-211, 2008.

NITERÓI. Fundação Municipal de Niterói. Portaria n. 01 de 2013. Disponível em: <www.educacaoniteroi. com.br>. Acesso em: 26 jul. 2015. 
NOVOA, A. Professores: imagens do futuro presente. Lisboa: Educa, 2009. (Capítulo 2: Para uma formação de professores construída dentro da profissão).

PARO, V. Escola de Tempo Integral: Desafio para o Ensino Público. São Paulo: Cortez, 1988.

PERRENOUD, P. A Prática Reflexiva no Ofício de Professor: Profissionalização e Razão Pedagógica. Porto Alegre: ArtMed, 2002.

PUStiglione, L. C. A. B. A Fundação Municipal de Educação de Niterói/RJ: efeitos na educação pública do município. Dissertação de Mestrado - UFRJ- Rio de Janeiro, 2014. 144 f.

SILVA, T. T. S. O Currículo como fetiche. Belo Horizonte: Autêntica, 2010.

SHIROMA, E. O; EVANGELISTA, O. A colonização da utopia nos discursos sobre profissionalização docente. PERSPECTIVA, Florianópolis, v. 22, n. 02, p. 525-545, jul./dez. 2004.

TARDIF, M. Saberes docentes e formação profissional. Petrópolis: Vozes, 2002.

VASCONCELLOS, K. R. T. Formação Continuada na Escola Municipal Anísio Teixeira: Um olhar sobre a formação docente. Dissertação de Mestrado - UNIRIO - Rio de Janeiro, 2016. 137 f.

VASCONCELLOS, K. R. T.; BERNADO, E. S. Profissionalização Docente: Reflexões e Perspectivas no Brasil. Educação \& Formação, Fortaleza, v. 1, n. 2, p. 208-222, maio/ago. 2016 Programa de Pós-Graduação em Educação da UECE http://seer.uece.br/?journal=redufor ISSN: 2448-3583

Artigo recebido em: $31 / 05 / 2017$

Aprovado em: 25/09/2017

\section{CONTATO PARA CORRESPONDÊNCIA:}

Elisangela da Silva Bernado.E-mail: efelisberto@yahoo.com.br

NOTAS

1 Esta investigação é um braço da pesquisa "Escolas Públicas no Estado do Rio de Janeiro e o Programa Mais Educação: uma análise das ações dos gestores escolares em busca de uma educação de qualidade", aprovada no edital Jovem Cientista do Nosso Estado de 2014, coordenado pela Prof. a Dra. Elisangela da Silva Bernado.

2 Todos os alunos na Rede Municipal de Educação de Niterói, às quartas-feiras, saem duas horas mais cedo. Este tempo é utilizado para planejamento semanal coletivo dos professores. Assim, a EMAT, sendo integral, funciona no seguinte formato: $2^{a}, 3^{a}, 5^{a}, 6^{a}$ de $8 \mathrm{~h}$ até as $17 \mathrm{~h} .4^{\mathrm{a}}$ de $8 \mathrm{H}$ às $15 \mathrm{~h}$. 